To Maega $\mid$ Jurnal Pengabdian Masyarakat

Februari 2021, Vol. 4, No. 1, hal, 81-89

$\operatorname{ISSN}(P): 2622-6332 ; \operatorname{ISSN}(E): 2622-6340$

http://www.ojs.unanda.ac.id/index.php/tomaega

\title{
Pelatihan Bagi Karyawan KSPPS Al Huda Wonosobo Untuk Menilai Kelayakan Usaha Calon Anggota
}

\section{Salihah Khairawati ${ }^{1,}{ }^{*}$, Sugeng Widodo ${ }^{2}$, Sugeng Nugroho Hadi ${ }^{2}$}

${ }^{1}$ Prodi Manajemen Syariah, STEI Hamfara, Yogyakarta

2 Prodi Perbankan Syariah ,STEI Hamfara, Yogyakarta

Correspondent Email : salihahkh@steihamfara.ac.id

\author{
Article History:
}

Received: 21-11-2020; Received in Revised: 23-12-2020; Accepted: 02-01-2021

DOI: http://dx.doi.org/10.35914/tomaega.v4i1.518

\begin{abstract}
Abstrak
Tujuan pengabdian pada masyarakat ini adalah memberikan bekal kepada karyawan KSPPS (Koperasi Simpan Pinjam Pembiayaan Syariah) Al Huda Wonosobo untuk menilai kelayakan usaha dari (calon) anggota yang mengajukan permohonan pembiayaan. Kegiatan pelatihan ini diikuti oleh staff marketing dan manajer dari 17 cabang KSPPS Al Huda yang tersebar di Kabupaten Wonosobo dan Banjarnegara, Jawa Tengah. Pelatihan dilakukan selama dua sesi dan diisi oleh tiga narasumber yang secara bergantian memberikan pemaparan mengenai pentingnya melakukan penilaian kelayakan usaha ditinjau dari berbagai perspektif agar organisasi dapat meminimalkan resiko kesalahan penilaian pembiayaan dan kerugian bagi organisasi. Selain itu pada sesi ini juga disampaikan pentingnya organisasi bisnis menjadi organisasi pembelajar dan siap untuk beradaptasi terhadap perubahan. Pada akhir sesi pelatihan peserta menyusun tabel indikator kelayakan usaha yang akan menjadi pedoman ketika peserta melakukan survey kelayakan usaha. Implikasi dari pelatihan ini meningkatnya kemampuan analisis kelayakan usaha di kalangan tenaga marketing dan manajer yang pada jangka panjang mendorong peningkatan kinerja organisasi.
\end{abstract}

Kata Kunci: pelatihan, studi kelayakan usaha, staf marketing, manajer.

\begin{abstract}
The purpose of this community service is to provide supplies to employees of KSPPS (Koperasi Simpan Pinjam Pembiayaan Syariah) Al Huda Wonosobo to assess the business feasibilitiy of its financing customers. This training activity was attended by marketing staff and managers from 17 branches of KSPPS Al Huda spread across Wonosobo and Banjarnegara districts, central Java. The training were conducted during two sessions and taught by three speakers who alternately provide exposure on the importance of conducting feasibility assessments of efforts reviewed from various perspectives so that the organization can minimize the risk of financing errors and losses for the organization. In addition, this session also conveyed the importance of business organizations becoming learner organizations and ready to adopting the changes. At the end of the training session, participants compiled a table of business feasibility indicators that will become guidelines when participants conduct a business feasibility survey. The implications of this training are the increasing ability to analyze business feasibility among marketing personnel and managers who in the long run encourage the improvement of the organization's performance.
\end{abstract}

Key Word: training, feasibility study, marketing officers, managers.

(C)To Maega / Jurnal Pengabdian Masyarakat. This is an open access article under the CC BY-SA 4.0 license (https://creativecommons.org/licenses/by-sa/4.0/). 

Februari 2021

\section{Pendahuluan}

Lembaga keuangan syariah (LKS) merupakan lembaga keuangan yang beroperasional dan berjalan dengan prinsip syariah Islam. Salah satu bentuk dari lembaga keuangan syariah adalah Koperasi Simpan Pinjam Pembiayaan Syariah (KSPPS). Jika dilihat dalam konteks sejarah, kelahiran lembaga keuangan mikro seperti BMT dilatarbelakangi oleh keterbatasan masyarakat lapis bawah untuk mengakses modal sebagai penguatan perekonomiannya (Lubis, 2016). KSPPS yang dahulu dikenal dengan nama Koperasi Jasa Keuangan Syariah atau Baitul Maal Wat Tamwil (KJKS-BMT) adalah sistem intermediasi keuangan di tingkat mikro yang berbadan hukum koperasi yang dalam operasionalnya dijalankan dengan prinsip-prinsip syariah, membantu masyarakat dalam memenuhi kebutuhan hidupnya berupa pembiayaan serta membantu menyediakan modal kerja bagi masyarakat untuk mengembangkan usahanya (Arwin, 2020); (Rachmawati \& Karim, 2020).

Prinsip syariah Islam ini berbeda dari perbankan atau lembaga keuangan konvensional. Lembaga keuangan syariah merupakan lembaga yang berdedikasi untuk meningkatkan kesejahteraan masyarakat. Lembaga keuangan syariah mikro yang dikenal dengan KJKS (Koperasi Jasa Keuangan Syariah) memberikan kontribusi pemberdayaan usaha mikro dan menegah dalam menambah modal ventura ke UMKM guna pengembangan bisnis (Mulia, 2019) . Menurut Fitriana (2016) beberapa poin penting yang berdampak pada keberadaan KJKS antara lain: prosedur pengajuan pembiayaan sederhana, pembiayaan dinilai tidak semata-mata berdasarkan nilai agunan melainkan lebih cenderung kelayakan usaha, pengembalian pembiayaan dapat dilakukan secara fleksibel, sistem pengelolaan resiko berbagi keuntungan dan resiko, serta lokasi yang mudah dijangkau.

Pengawasan atas pelaksanaan prinsip-prinsip syariah pada lembaga keuangan syariah (LKS) menjadi sesuatu yang sangat urgen dan utama untuk dilaksanakan di mana hal itu merupakan core atau inti dari operasional lembaga keuangan syariah. Lembaga Keuangan Syariah (LKS) tidak hanya dituntut bertanggung jawab tentang kuantitas perhitungan angka laba, sebab selain laba ada pula keyakinan bahwa ia kelak harus mempertanggungjawabkan pengelolaan LKSnya kepada Allah. LKS harus konsisten untuk melakukan tanggung jawab terhadap penerapan prinsip syariah. LKS hidup di tengah-tengah masyarakat dengan mengusung platform syariah (Budiono, 2017).

Kesalahan-kesalahan dalam pengambilan keputusan pembiayaan harus dapat ditekan guna menghindari resiko kerugian dan pembiayaan bermasalah. Sebagaimana hasil penelitian yang dilakukan bahwa KJKS mengalami permasalahan disebabkan oleh kelemahan para analis pembiayaan antara lain: kurang tajam dalam melakukan analisis pembiayaan, kurang mendalami bisnis dari anggota/ nasabah dan kalah pengetahuan dibanding anggota/nasabah (Faniyah \& Azhari, 2019). 
Mengingat peranan sumberdaya manusia yang berada di garda depan sangat penting, maka organsasi perlu membekali karyawannya dengan pengetahuan dan keterampilan. Dalam banyak penelitian memberikan bukti bahwa pelatihan berpengaruh secara signifikan terhadap kemampuan kerja (Ratnasari \& Sunuharyo, 2018). Salah satunya adalah pengetahuan mengenai penilaian kelayakan usaha.

Selama ini seringkali faktor keuntungan atau keuangan menjadi satu satunya indikator kelayakan suatu usaha. Perlunya menggeser paradigma ini, bahwa kelayakan usaha didukung oleh banyak faktor. Ada beberapa faktor yang harus dipertimbangkan dalam menilai kelayakan usaha yakni aspek legalitas, pasar, produksi atau tekhnis lingkungan (Wayan et al., 2020), sosial dan ekonomi (Nainggolan, 2018). Dalam menjalankan bisnis, tentu ada banyak hal yang harus diperhatikan. Apa pun yang dapat mempengaruhi perusahaan perlu diperhitungkan. Melalui studi kelayakan usaha atau bisnis, pelaku usaha dapat mengetahui informasi mengenai posisi bisnis saat ini. Melihat sebuah usaha sebagai suatu sistem yang holistik pelaku akan dapat melakukan perbaikan dan pengendalian lebih baik (Turner \& Endres, 2017). Menurut Chang, et.al, (2018) manajemen mutu dan layanan kepada konsumen merupakan unsur yang penting dalam organisasi.

Melalui pelatihan ini diharapkan karyawan akan dapat meningkatkan kompetensi dan profesionalisme dalam bekerja. Dalam jangka panjang akan berdampak pada keberlangsungan serta peningkatan kinerja organisasi.

\section{Metode}

Tujuan dari kegiatan pengabdian kepada masyarakat ini adalah memberikan pelatihan kepada staff KSPPS Al Huda bagaimana untuk melakukan analisis kelayakan usaha secara benar dan komprehensif, sehingga membantu pembuat keputusan untuk membuat keputusan pembiayaan atau invetasi secara tepat dan terhindari dari resiko kerugian. Selain itu pelatihan ini juga memberikan kesempatan peserta untuk terlibat aktif dalam membuat atau menyusun tabel rencana analisis kelayakan usaha, yang pada akhirnya akan membantu meningkatkan kompetensi kerja peserta pelatihan.

Metode yang digunakan dalam pengabdian kepada masyarakat berupa pelatihan (in house training). Kegiatan pelatihan dilakukan di KSPPS (koperasi simpan pinjam syariah) Al Huda Wonosobo diikuti oleh 24 peserta yang merupakan staff marketing dan para manajer dari 17 cabang yang tersebar di Kabupaten Wonosobo dan Banjarnegara, Jawa Tengah. Kegitan pelatihan dilaksanakan pada 17 November 2020 dilakukan secara full day dari jam 08.30 hingga 15.30 WIB yang dibagi dalam dua sesi. 
[84] Salihah Khairawati, dkk / To Maega : Jurnal Pengabdian Masyarakat, Vol.4; No.1; Februari 2021

\section{Hasil dan Pembahasan}

\section{a. Diskrispsi kegiatan pra pelatihan}

Identifikasi masalah dilakukan dengan mengumpulkan pertanyaan dari lembaga KSPPS Al Huda mengenai analisis kelayakan usaha. Berangkat dari pertanyaan tersebut penulis menyimpulkan masih adanya perbedaan pandangan mengenai penilaian kelayakan usaha di kalangan staff marketing dan manajer, seperti menilai kelayakan usaha ditinjau dari aspek keuangan dan kehalalan saja, padahal ada aspek-aspek lain yang cukup penting yang harus menjadi pertimbangan dalam melakukan penilaian kelayakan usaha. Atas dasar itulah penulis melakukan pelatihan yang merupakan bagian dari upaya pemecahan masalah yang dihadapi masyarakat.

Kegiatan koordinasi dan assement dilakukan untuk mengetahui latar belakang peserta, tingkat pendidikan, dan kebutuhan peserta dan mitra dari kegiatan pengabdian ini. Kebutuhan dari peserta pelatihan:

1. Mengetahui pentingnya memahami penilaian kelayakan usaha dilihat dari berbagai perspektif.

2. Mengetahui tahapan dalam melakukan penilaian kelayakan usaha.

3. Mengetahui faktor-faktor yang harus diperhatikan dalam menilai kelayakan suatu usaha.

4. Mengetahui bagaimana cara membuat resume kelayakan usaha.

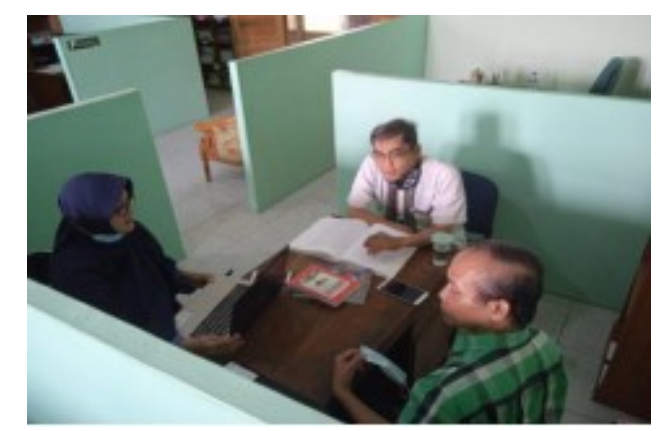

Gambar 1. Sinkronisasi materi dan kordinasi persiapan pelatihan

Pada tahap pra kegiatan ini meliputi menentukan jadwal yang disepakati mitra, peserta dan pemateri, tempat penyelenggaraan, sarana dan prasarana, sinkroniasai materi, pengembangan bahan pelatihan dari narasumber serta pembuatan handout pelatihan.

\section{b. Diskripsi pelaksanaan kegiatan}

Pada tahap ini, pemateri menjelaskan: pengertian dan manfaat analisis kelayakan usaha bagi bisnis dan bagi lembaga pembiayaan, aspek yang dikaji dalam analisis kelayakan usaha, hal-hal yang harus dihindari dalam melakukan analisa kelayakan usaha, bagaimana mencari data dan informasi dalam analisa kelayakan usaha. Pada sesi ini pembicara menjelaskan pentingnya kualitas informasi dan data mengenai calon nasabah dan usaha yang dimiliki nasabah. 
Pentingnya staff yang bertugas di lapangan memiliki kemampuan mitigasi, analisis dan riset sederhana. Salah satu yang masih jarang dimiliki lembaga keuangan sekelas koperasi adalah tim riset dan informasi. Disinilah pentingnya sinergi antara lembaga pendidikan dan lembaga usaha, agar saling mengisi. Hasil dari kegiatan ini adalah memberikan pemahaman yang seragam dan komprehensif bagaimana melakukan analisa kelayakan usaha bagi pelaku lembaga keuangan syariah, bagaimana mencari informasi dan data yang layak untuk menunjang pengambilan keputusan pembiayaan, selain itu dapat meningkatkan ketelitian dan kehati-hatian dalam melakukan analisis kelayakan usaha dengan menggeser paradigma lama bahwa kelayakan usaha hanya ditinjau dari aspek keuntungan atau keuangan dan kehalalan saja.
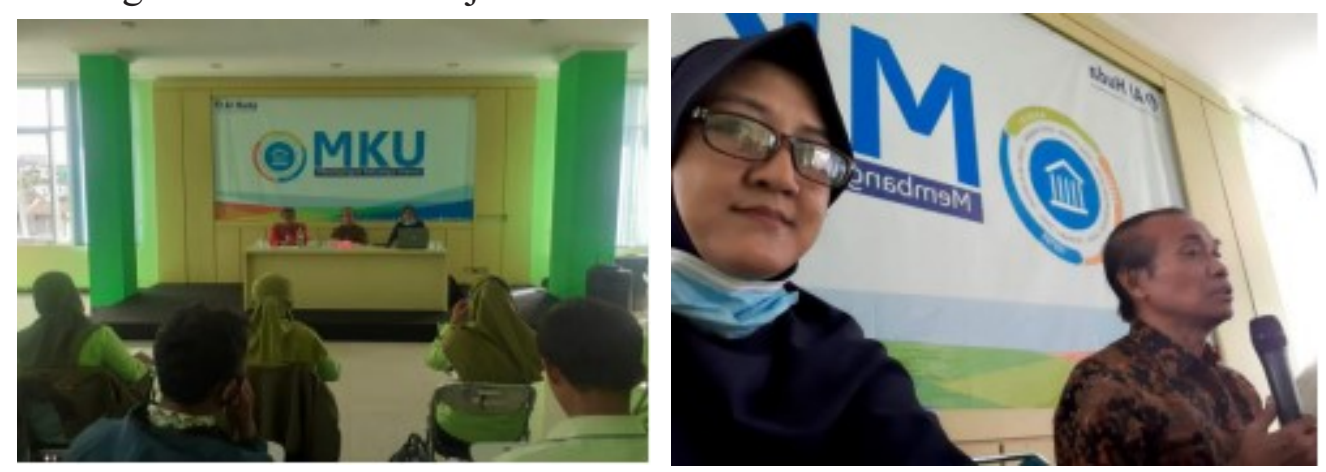

Gambar 2. Pelaksanaan Pelatihan

Mengingat koperasi syariah menyalurkan pembiayaan yang berasal dari dana masyarakat, maka penilaian kelayakan usaha perlu dilakukan secara komprehensif. Aspek-aspek yang harus dikaji dalam menganalisa kelayakan usaha antara lain:

1. Aspek legalitas : penilai perlu mempertimbangkan aspek legalitas dari usaha yang akan dibiayai meliputi badan hukum, kepemilikan usaha dan identitas calon nasabah, izin usaha, izin lokasi dan izin masyrakat.

2. Aspek pasar : penilai perlu mempertimbankan aspek pasar dari usaha yang akan dibiayai meliputi adanya gap antara permintaan dan penawaran, tingkat urgensi produk untuk dipenuhi, keunikan produk yang tidak dimiliki produk lain, permintaan akan produk yang terus tumbuh, intensitas persaingan yang mampu dihadapi pengusaha.

3. Aspek keuangan : penilai perlu mempertimbankan aspek keuangan dari usaha yang akan dibiayai meliputi arus kas, neraca keuangan, paybcak period, return on investment, pofitability index, Analisis BEP, rasio likuiditas, rasio aktivitas.

4. Aspek syariah : penilai perlu mempertimbankan aspek syariah dari usaha yang akan dibiayai meliputi niat dari pelaku usaha, jenis usaha yang halal, cara menjalankan usaha sesuai ajaran Islam. Sebagai sebuah lembaga bisnis syariah, maka aspek syariah tidak boleh dilalaikan.

5. Aspek sumberdaya manusia : penilai perlu mempertimbangkan aspek sumberdaya manusia dari usaha yang akan dibiayai meliputi cara pengelolaan 


\section{[ 86] Salihah Khairawati, dkk / To Maega : Jurnal Pengabdian Masyarakat, Vol.4; No.1;}

Februari 2021

sumber daya manusia, keterpenuhan kualitas dan kuantitas, kaderisasi sumberdaya inti.

6. Aspek produksi : penilai perlu mempertimbankan aspek produksi dari usaha yang akan dibiayai meliputi ketersediaan bahan baku, ketersediaan sarana dan prasarana pendukung, lokasi yang tepat.

7. Aspek lingkungan, ekonomi dan sosial : penilai perlu mempertimbangkan aspek lingkungan dari usaha yang akan dibiayai meliputi dampak terhadap lingkungan, upaya mengelola dampak terhadap lingkungan, dampak usaha terhadap ekonomi daerah, nasional, peningkatan kesejahteraan, dan peningkatan kualitas hidup.

Antusiasme peserta untuk mengikuti pelatihan dan menerima hal-hal yang baru menjadi alasan bagi pimpinan lembaga untuk menyelenggarakan pelatihan di KSPPS Al Huda untuk tahun yang akan datang. Dalam kegiatan pelatihan peserta juga dijelaskan beberapa metode penilaian kelayakan usaha dari sisi keuangan beserta contoh-contohnya, dengan pendekatan interaktif dimana peserta diminta untuk melakukan penghitungan. Pada akhir rangkaian acara pelatihan ini, peserta menyusun rencana tabel indikator kelayakan usaha yang akan mereka gunakan sebagai panduan dalam melakukan analisa usaha calon nasabah. Tabel ini berisi beberapa aspek meliputi aspek legalitas, keuangan, produksi, sumberdaya manusia, pasar, lingkungan dan ekonomi serta aspek syariah.
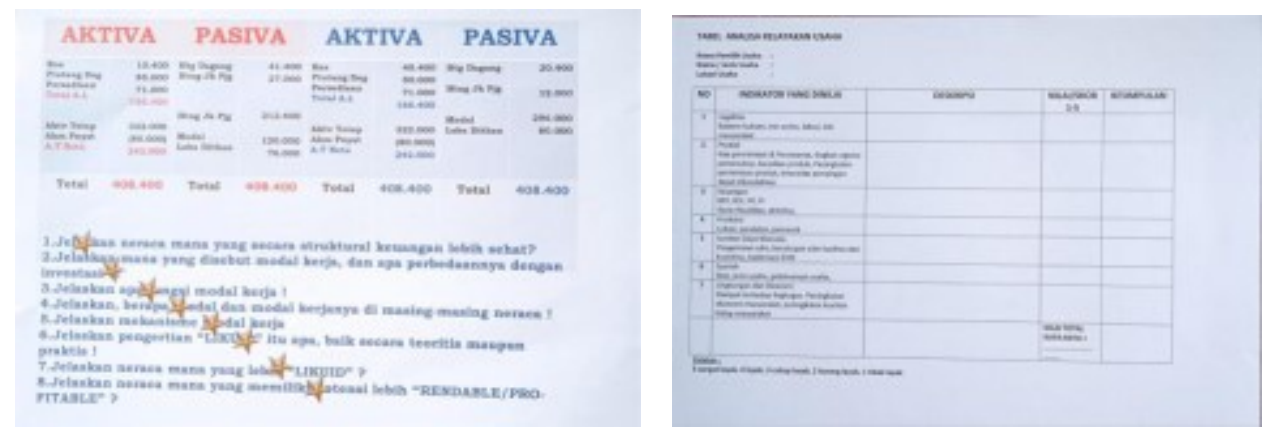

Gambar 3. Tabel Analisis Kelayakan Usaha
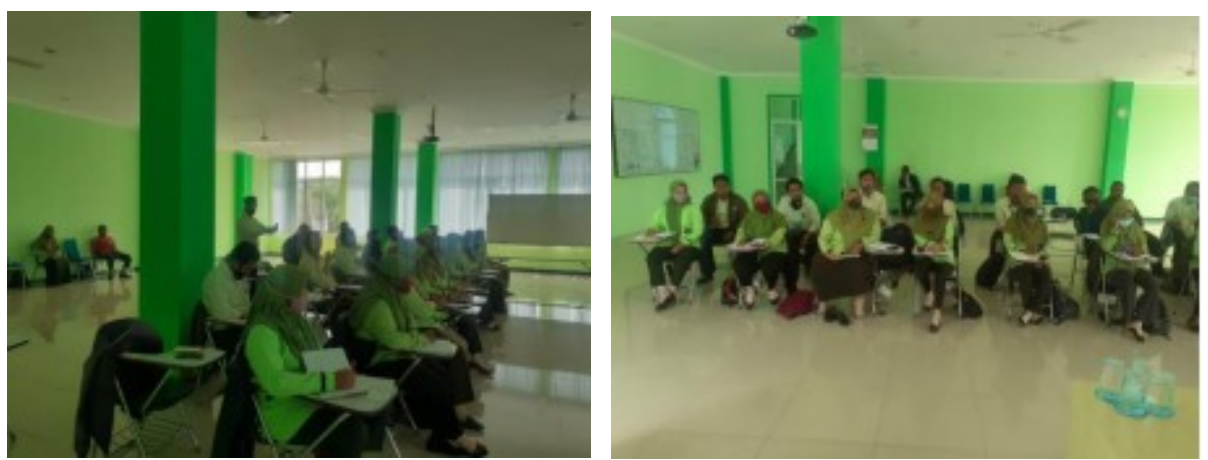

Gambar 4. Peserta menyusun rencana tabel dan menyimak evaluasi pemateri

(C)To Maega / Jurnal Pengabdian Masyarakat. This is an open access article under the CC BY-SA 4.0 license (https://creativecommons.org/licenses/by-sa/4.0/). 


\section{c. Keunggulan Pengabdian Kepada Masyarakat.}

Kegiatan pengabdian kepada masyarakat yang telah dilakukan ini memiliki beberapa keunggulan. Pertama, kegiatan ini membantu staff dan manajer KSPPS Al Huda untuk menyamakan persepsi tentang kriteria usaha yang layak dengan perspektif yang luas. Kedua, yang terlibat dalam pelatihan ini adalah staff marketing dan manajer yang telibat dalam realisasi pembiayaan. Ketiga, pelatihan ini juga memberikan motivasi kepada peserta untuk mau menjadi insan pembelajar yang selalu siap beradaptasi dengan perubahan zaman.

\section{d. Evaluasi pelaksanaan pengabdian kepada masyarakat.}

Secara umum, pelaksanaan kegiatan pengabdian masyarakat berjalan baik dan lancar. Seluruh peserta terlibat aktif dan antusias selama kegiatan pengabdian berlangsung. Meskipun demikian, terdapat beberapa kendala yang dihadapi oleh tim selama kegiatan pengadian ini, yaitu:

1. Pemahaman dasar-dasar manajemen keuangan di antara peserta belum mendalam, sehingga penjelasan mengenai analisis kelayakan usaha dengan pendekatan analisis investasi membutuhkan penjelasan yang panjang dan memakan waktu.

2. Materi yang disampaikan kepada peserta lebih mengedepankan pendekatan kualitatif, artinya menilai kelayakan usaha masih dilakukan dengan analisis deskripsi scoring per indikator masih belum rinci.

\section{Kesimpulan}

Program kerjasama kemitraaan yang dilakukan pada staff dan manajer KSPPS Al Huda berupa pelatihan penilaian kelayakan usaha dirasakan manfaatnya. Hal itu ditandai dengan adanya kesamaan pemahaman di kalangan peserta mengenai faktor-faktor yang menjadi perimbangan dalam menilai kelayakan usaha, bukan hanya aspek keuntungan atau finansial semata, melainkan aspek-aspek lain termasuk juga aspek syariah yang menjadi acuan penting dan paling utama bagi sebuah lembaga bisnis syariah. Diharapkan pasca pelatihan para staff yang bertugas melakukan survey, analisis data serta manajer lebih hati-hati dalam membuat keputusan investasi atau pembiayaan terhadap usaha (calon) anggota/nasabah sehingga terhindar dari resiko kerugian. Terlebih lagi sumber dana pembiayaan berasal dari pihak ketiga (masyarakat luas) yang harus dikelola dengan penuh kehati-hatian dan amanah.

Di masa yang akan datang diharapkan kegiatan pelatihan serupa dilaksanakan dengan memberikan dasar-dasar pemahaman mengenai manajemen keuangan terlebih dahulu, sehingga peserta lebih mudah memahami analisis kelayakan usaha dengan pendekatan analisis investasi. Selain itu peserta perlu dikenalkan metode penilaian kelayakan usaha dengan pendekatan kuantitatif. 


\section{Ucapan Terimakasih}

Ucapan terima kasih kami sampaikan kepada P3M STEI Hamfara yang telah melakukan persiapan, pengkondisian dan memberikan dukungan terhadap jalannya kegiatan pengabdian kepada masyarakat. Begitu juga kepada KSPPS Al Huda Wonosobo yang telah memberikan kepercayaan kepada tim PKM untuk memberikan kesempatan pelatihan dan sharing kepada para staffnya.

\section{Daftar Pustaka}

Arwin. (2020). Peranan bmt terhadap pemberdayan usaha mikro (Kasus, Studi Padang, BMT Al-furqon Kab, Sibusuk Prop, Sijunjung Barat, Sumatera). Jurnal Al Mashaadir, 1(2), 120-128.

Budiono, A. (2017). Penerapan prinsip syariah pada lembaga keuangan syariah. Jurnal Law and Justice, 2(1), 54-65.

Chang, R. D., Zuo, J., Zhao, Z. Y., Soebarto, V., Lu, Y., Zillante, G., \& Gan, X. L. (2018). Sustainability attitude and performance of construction enterprises: A China study. Journal of cleaner production, 1714401451.https://doi.org/10.1016/j.jclepro.2017.10.277

Faniyah, I., \& Azhari. (2019). Pelaksanaan Prinsip Syariah Dalam Memberdayaka Usaha Mikro dan Kecil Pada Koperasi Jasa Keuangan Syariah Baitul Maal Wat Tamwil (KJKS-BMT) Sejahtera Padang. Jurnal Hukum Sasana, 5(2), $125-135$.

Fitriana, W. (2016). Lembaga Keuangan Mikro Syariah: Eksistensi dan Aksesibilitasnya Bagi Pembiayaan Usahatani di Sumatera Barat (Studi Kasus: Koperasi Jasa Keuangan Syariah (KJKS) Baitul Maal Wat Tamwil (BMT)). Jurnal Agribisnis Indonesia, 4(2), 149-162.

Lubis, F. A. (2016). Peranan BMT dalam Pemberdayaan Ekonomi Nasabah Di Kecamatan Berastagi-Kabanjahe Kabupaten Karo ( Studi Kasus Bmt Mitra Simalem Al-Karomah ). HUMAN FALAH, 3(2), 272-195.

Mulia, R. A. (2019). Peranan Program Koperasi Jasa Keuangan Syariah Baitul maak wat Tamwil ( KJKS BMT) Rizki Dalam Pemberdayaan Pelaku Usaha Mikro Kecil Menengah Di Kota PADANG, Ensiklopedia Social Review, 1(3), 290-299.

Nainggolan, O. V. B. (2018). Feasibility Analysis of Small and Medium Enterprises of Shoes and Slippers in Bogor. In Advances in Economics, Business and Management Research,3rd Global Conference On Business, Management, and Entrepreneurship (GCBME 2018) Feasibility (Vol. 117, pp. 166-169). Atlantis Press.

Ratnasari, M. D., \& Sunuharyo, B. S. (2018). Pengaruh Pendidikan dan Pelatihan Terhadap Karyawan Melalui Variabel Mediator Kemampua Kerja Karyawan (Studi Pada Karyawan Pt Petrokimia Gresik ). Jurnal Administrasi Bisnis (JAB)|V, 58(1), 210-218.

Rachmawati, W., \& Karim, A. (2020). Analisis Peran KSPPS Dalam Mendukung Ekonomi Rakyat Berbasis Usaha Menengah Kecil, AKURAT| Jurnal Ilmiah 
[89] Salihah Khairawati, dkk / To Maega : Jurnal Pengabdian Masyarakat, Vol.4; No.1; Februari 2021

Akuntansi FE UNIBBA, 11(April), 7-18.

Turner, S., \& Endres, A. (2017). Strategies for Enhancing Small-Business Owners

' Success Rates Background : History and Importance of Small Business in the United States. International Journal of Applied Management and Technology, 16(1), 34-49. https://doi.org/10.5590/IJAMT.2017.16.1.03

Wayan, N., Sudiartini, A., Agung, A., Astari, E., Kardini, N. L., \& Dhani, Y. R. (2020). The Feasibility Study of Coffee House Business Opportunity in COVID-19 Pandemic: A Case Study at Kulo Coffee Shop Pemogan. International Research Journal of Management, IT and Social Sciences, $7(5), 38-45$. 